\title{
Analysis of thermal performance of cementitious compounds using soda-lime glass and infrared thermography
}

\author{
Rosemary Bom Conselho Sales ${ }^{1, a}$, Fernando Augusto Sales ${ }^{2, b}$, Cristiane do \\ Bom Conselho Sales Alvarenga ${ }^{2, \mathrm{c}}$, Maria Teresa Paulino Aguilar ${ }^{3, \mathrm{~d}}$ \\ ${ }^{1}$ Minas Gerais State University - CDETec - UEMG, Brazil \\ ${ }^{2}$ Federal Technology Education Center of Minas Gerais - CEFET-MG, Brazil \\ ${ }^{3}$ Minas Gerais Federal University - UFMG, Brazil \\ arosebcs@gmail.br, bfdosales@gmail.com, crisbcs@gmail.com, deresa@ufmg.br
}

\begin{abstract}
Keywords: cementitious composites, concrete, thermography, non-destructive testing.
Abstract. The use of waste from both industrial and agricultural sources or from the construction sector itself as alternative materials to partially or totally replace the aggregates or agglomerates of concrete/mortar has been an interesting option for obtaining eco-efficient cement compounds. The most commonly used wastes are blast furnace slag, silica fume, fly ash and waste from construction and demolition activities. Other interesting options are related to the use of sugarcane bagasse ash and glass waste. Despite the importance of cementitious compounds, there are few reports on their thermal performance, once the thermal comfort of the built environment is closely associated with the capacity of building materials to absorb, store and transmit heat to their interior. Published works indicate that replacing part of the cement with microparticles of soda-lime glass microparticles can contribute to the production of mortars and concretes of similar mechanical performance and workability, and the production of concretes durable in regard to the inhibition of the alkali-aggregate reaction. Accordingly, this study evaluated the thermal performance of mortars made with partial replacements of cement (10\% and 20\%) per colorless soda-lime glass microparticles and amber, and analyzed the results in relation to the surface temperature of materials after natural exposure to sunlight.
\end{abstract}

\section{Introduction}

Different studies have investigated the use of glass waste in Portland cement compounds, either as aggregate or supplementary cementitious materials ${ }^{[[1],[2],[3]]}$. These studies do not have a consensus around the influence of the color and size of glass particles on the behavior of the produced compounds. Therefore, the reaction of silica with the alkali can be beneficial if it occurs during curing, or deleterious, if it occurs in hardened concrete ${ }^{[[4],[5],[6]]}$. Recent studies show that the partial replacement of cement with soda-lime glass microparticles can contribute to the production of mortars of similar mechanical performance and the production of durable cementitious compounds in relation to inhibiting the alkali-aggregate reaction ${ }^{[7],[8]]}$. We identified the influence of the glass color expressed in terms of its chemical composition, hydration heat, setting time and electrical resistivity. In terms of sustainability in construction, it is important to evaluate the thermal comfort of the built environment, which is closely related the ability of materials to absorb, store and transmit heat to the inside. There are few published data on the thermal performance of cementitious compounds with the use of waste, in particular glass waste.

Infrared thermography is a nondestructive and noninvasive technique that inspects the temperature range of a surface through the image generated by the thermal radiation emitted in the infrared range ${ }^{[[9],[10]]}$. The adoption of this technique allows for monitoring the thermal behavior of buildings, in addition to identify and analyze problems considered unapproachable by other methods. Based on the theory that all bodies above absolute zero $\left(-273^{\circ} \mathrm{C}\right)$ absorbs and emits thermal radiation ${ }^{[[11]]}$, thermography enables us to measure and evaluate the characteristics of materials in a number of investigations involving the heat transfer phenomena. Hence, this study uses infrared thermography to 
evaluate the thermal performance of mortars made with soda-lime glass microparticles, both amber and colorless, to partially replace Portland cement in $10 \%$ and $20 \%$.

\section{Materials and methods}

Cementitious compounds were produced with and without the partial replacement of cement by amber and colorless glass waste obtained by grinding the soda-lime glass in laboratory. The used cement was Portland of high early strength, plus natural silica sand and a water/cement ratio of 0.48. The amber and colorless residues showed chemical compositions typical of soda-lime glass ${ }^{[3]]}$. The registered differences between the two types of glasses were seen in aluminum oxides, ferric oxides and more strongly, the content of sodium oxide. Also, the amber glass showed a higher content of volatile/organic matter, which indicates that carbon can be the differential element in the composition of the analyzed glasses. The average particle size for the colorless and the amber glasses was $\mu 8.93$ and $10.61 \mathrm{~m}$, respectively. The obtained X-ray diffractograms revealed diffuse spectra which are commonly attributed to glass phases ${ }^{[[12]]}$, indicating that the material has characteristics of non-crystalline material. The heat distribution patterns of the material under study were evaluated by infrared thermography.

For a better control of the experiments, the thermal behavior was initially evaluated only for the amber and the colorless glass microparticles. The residues were placed inside containers of the same materials (polypropylene) and were exposed to direct sunlight for 10 minutes whereas the reached temperatures were recorded.

The cementitious compounds prepared with cement, sand and water were afterwards analyzed with and without replacing the cement mass by $10 \%$ and $20 \%$ of amber and colorless glass microparticles. For each situation, two cylindrical samples of $5 \times 10 \mathrm{~mm}$ have been manufactured. After the curing period, the samples were grouped by type and remained in a stable environment for 24 hours until the thermal equilibrium was established. Special care was taken with the surrounding area during the reading process, since the infrared camera captures the temperature of the object and the points close to it, whereas the reading showed an arithmetic average of the temperatures of all points read in the influence area. Thus, we have used two polystyrene slides $(10 \times 10 \times 1 \mathrm{~mm})$ to isolate samples from contact with other materials and maintain a uniform background radiation (Figure 1).

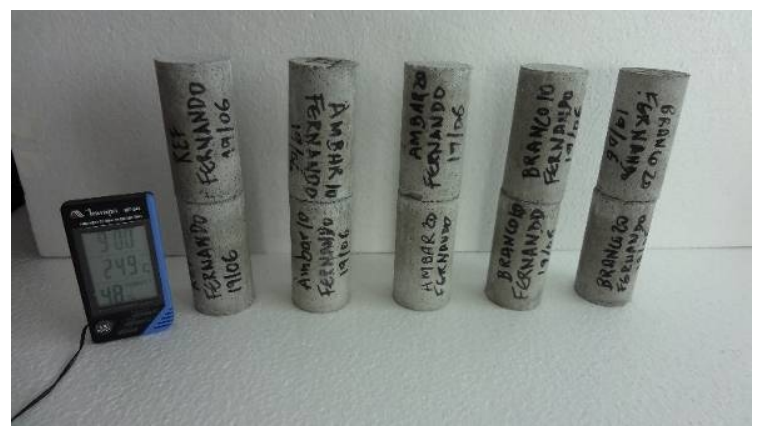

Figure 1 - Thermography samples before sunlight exposure.

For evaluation the temperatures of samples, we have used an infrared camera - Thermacam, of the Flir brand, model $\mathrm{P} 640$, temperature range $-40^{\circ} \mathrm{C}$ to $500^{\circ} \mathrm{C}$ and accuracy of $\pm 2 \%$ of the measurement reading. To define the study parameters, we have adopted a reflected temperature of $50^{\circ} \mathrm{C}$, air temperature of $20^{\circ} \mathrm{C}$, relative humidity of $50 \%$ and emissivity of 0.95 . The distance between the device and the sample was $1.50 \mathrm{~m}$ and the ambient temperature was recorded by a thermo-hygrometer clock (Minipa MT-241). The place used for the test was an outdoor area with intense sunlight. The test duration was four hours and thirty minutes. Thermographic images were collected every 30 minutes of exposure to the sunlight. Images were analyzed using the software QuickReport, whereas graphics were made in Microsoft Excel. 


\section{Results}

Thermograms of Figure 2 show results relative to the temperature of the detected colorless and amber glass microparticles (minimum/maximum). In the analysis of results, special attention should be addressed to the color scale, as colors indicate the recorded temperatures (before and after insolation). The initial temperatures of amber and colorless glass residues were $26.2^{\circ} \mathrm{C}$ and $26.7^{\circ} \mathrm{C}$, respectively (difference in camera measurement uncertainty). After 10 minutes of sunlight, amber and colored glass microparticles showed lower temperatures, i.e., $57.9^{\circ} \mathrm{C}$ for the colorless residue and $50.5^{\circ} \mathrm{C}$ for the amber glass. The materials absorbed/emitted heat differently: the amber glass microparticles were seen to be $6.9^{\circ} \mathrm{C}$ below the colorless microparticles. That could be related to the higher carbon content in the sample, considering that this element has high thermal conductivity $(129 \mathrm{~W} /(\mathrm{m} . \mathrm{K})$.
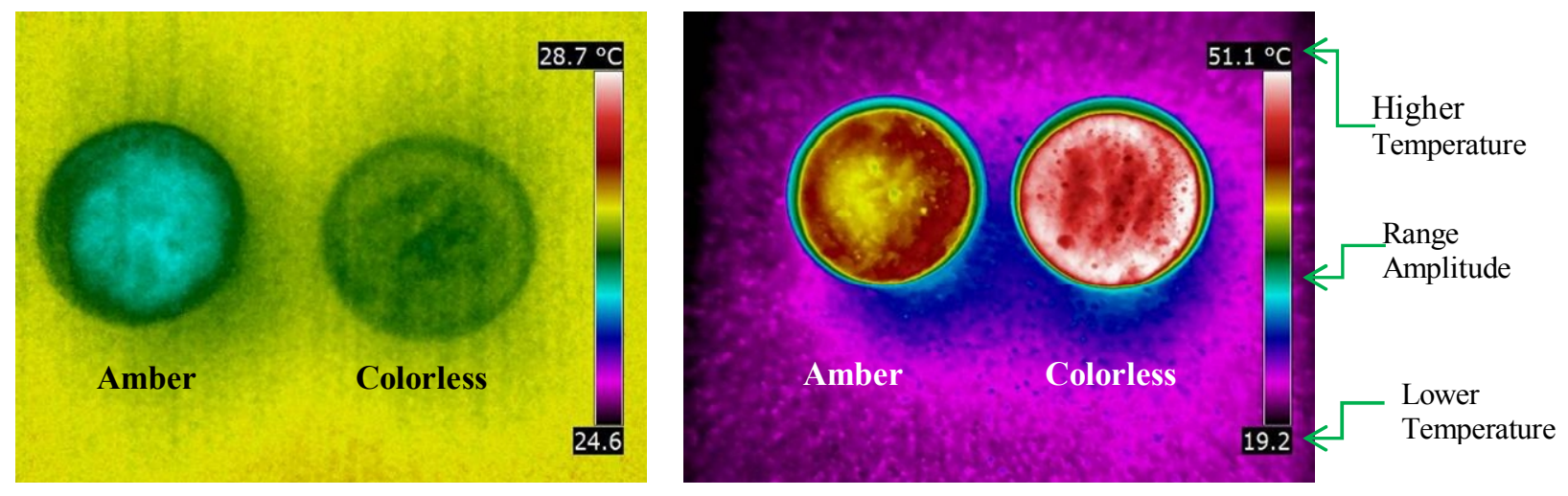

Figure 21 - Thermograms of amber and colorless microparticles before and after 10 minutes of exposure to sunlight

Data from Figure 3 show the values obtained on the sample surface of mortars made with and without the partial replacement of cement by glass microparticles during the first 90 minutes of exposure to sunshine.

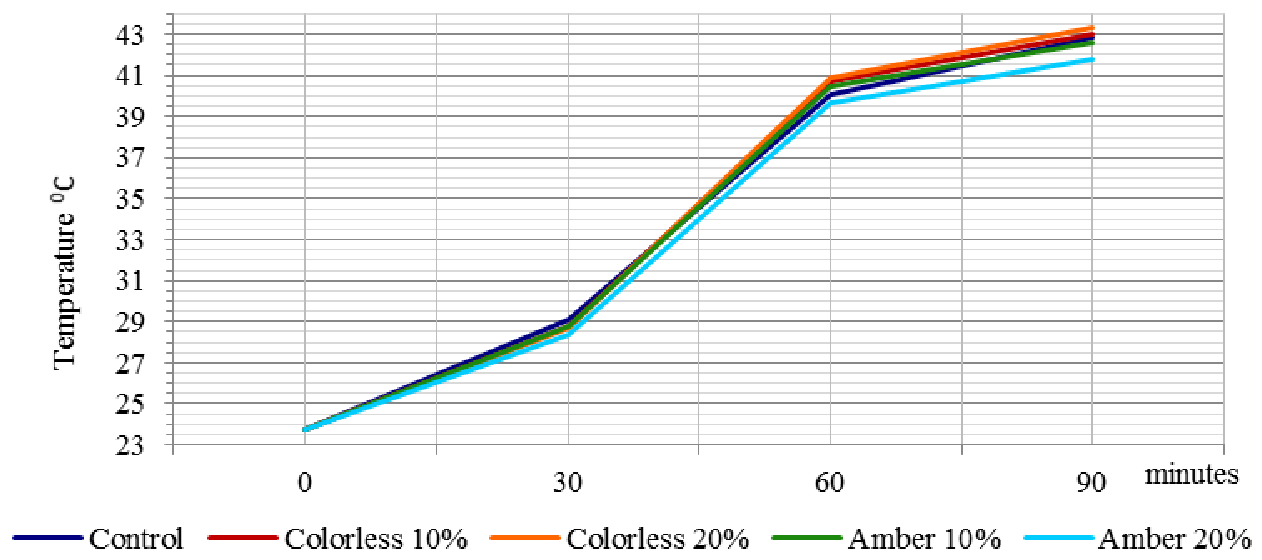

Figure 3 - Thermography results: temperatures of mortars in the first 90 minutes.

The graphic shows that all samples were under thermal equilibrium at the start of the test $\left(23.7^{\circ} \mathrm{C}\right)$. After 30 minutes, the temperature was seen to have increased in $5^{\circ} \mathrm{C}$ temperature and continued to during the 60 minutes. At the 90 minutes of exposure to sunlight, the elevation was more marked, around $19^{\circ} \mathrm{C}$. These results are consistent with studies conducted by Silva Junior ${ }^{[[13]]}$ on polymeric composites made from natural pineapple leaf fibers, and Alvarenga ${ }^{[14]]}$ on geopolymeric microconcretes whose compounds showed a marked temperature increase in the early hours of sunshine. Despite the values of the sample containing $20 \%$ of the cement replacement by amber glass microparticles exhibited a slight temperature drop as compared to the other samples, it can be considered within the camera's measurement uncertainty. 
Figure 4 shows the sequence of measurements (at 120, 150, 180, 210, 240 and 270 minutes of exposure to sunlight). Results clearly show that temperature of mortars continued to rise at 120,150 and 180 minutes, and at 210, 240 and 270 minutes, with minor intensity. All samples had a temperature drop at 210 minutes, possibly due to the emergence of clouds in the sky. The maximum temperature was reached at the 240 minutes of test. Although the samples absorb/emit heat in a similar way, the test body containing $20 \%$ of amber glass microparticles exhibited lower temperatures than the other samples. The sample containing $20 \%$ of colorless glass microparticles was slightly above the rest. This could indicate that higher levels of the cement replacement by colorless glass microparticles contribute to higher heat emission by compounds during exposure to sunlight. Samples made of $10 \%$ (colorless and amber) had temperatures very close to those of the control samples. A replica of the tests was carried out and the same result was found. Thus, one can infer that the use of amber glass microparticles is a possible method to control the thermal performance of mortars/concretes.

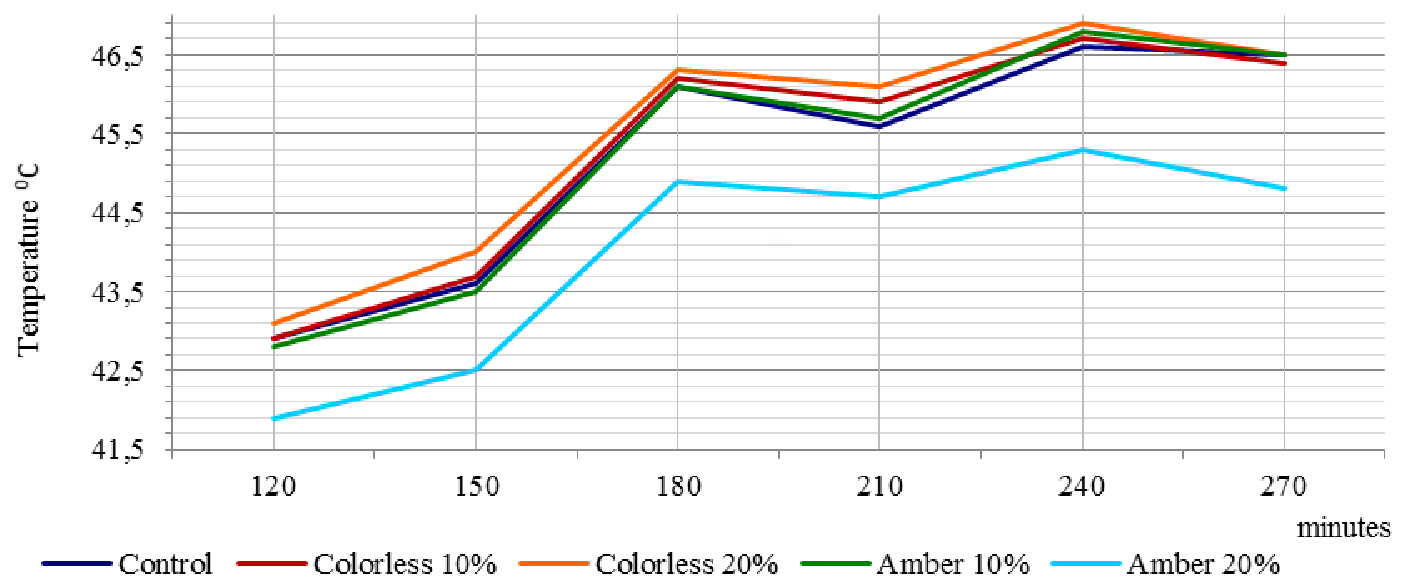

Figure 4 - Mortar temperature after four hours and 30 minutes of sunshine exposure.

\section{Conclusions}

Thermography revealed significant differences in the temperatures of composites manufactured with and without replacement of cement by glass particles after sunlight exposure. Samples containing $20 \%$ amber glass showed different temperatures when compared to the others, emitting less heat to the environment during exposure to sunlight. Further studies should be conducted so as to monitor the cooling of samples and therefore achieve a comprehensive approach of the heating-cooling cycle to which the building materials are daily exposed.

\section{Acknowledgements}

The authors are thankful to the Minas Gerais State Research Support Foundation (FAPEMIG) and the Brazilian National Council for Scientific and Technological Development (CNPq) for the financial support provided to this research.

\section{References}

[1] J.C. Phillips, D.S. Cahn. Refuse glass aggregate in Portland cement. In: Proceedings of the 3 rd mineral waste utilisation symposium. Mar. 14-16, US Bureau of Mines, Chicago, (1972) pp. 386-390.

[2] C. Meyer, S. Baxter, W. Jin. Potential of waste glass for concrete masonry blocks. In: Proceedings of the fourth materials engineering conference. Washington (1996) p. $666-73$. 
[3] C. Shi, K. Zheng, A review on the use of waste glasses in the production of cement and concrete. Resources, Conservation and Recycling, v. 52, (2007) p. 234-247.

[4] M. Cyr, P. Rivard, F. Labrecque. Reduction of ASR-expansion using powders ground from various sources of reactive aggregates. Cem Concr Compos, v. 31, n. 7, (2009) p. 438-46.

[5] L.A. Pereira-de-Oliveira, J.P. Castro-Gomes, P.M.S. Santos, The potential pozzolanic activity of glass and red-clay ceramic waste as cement mortars componentes. Construction and Building Materials, v. 31, (2012) p. 197-203.

[6] C. Yuksel, R. S. Ahari, B. A. Ahari, K.Ramyar. Evaluation of three test methods for determining the alkali-silica reactivity of glass aggregate. Cement \& Concrete Composites, v. 38, (20013) p. 57-64.

[7] F. A. Sales, R. B. C. Sales, E. C. S. Corrêa N. D. S. Molhallem and AGUILAR M. T. P. Study of the durability ofmortar for structural concrete made with fine powder of white glass. In XIII International Conference on Durability of Building Materials and Components. São Paulo. Brasil. v.I, (2014) p. 984-993.

[8] A.M. Matos, J.S. Coutinho, Durability of mortar using waste glass powder as cement replacement. Construction and Building Materials, v. 36, (2012) p. 205-215.

[9] C.I. Castanedo, X. Maldague Defect depth retrieval from pulsed phase thermographic data on plexiglas and aluminum samples. Thermosense XXVI, v. 5405, Society of Photo-optical instrumentation engineers, (2004).

[10] R.B.C. Sales, F.A. Sales, S.G. Tavares, R. M. Andrade, M. T. P. Aguilar. Thermal analysis of structural masonry in concrete block containing expanded polystyrene (EPS) using digital infrared thermal image. 10TH. In: International Conference on Quantitative Infrared Thermography. Québec -NCanada, (2010).

[11] F. P. Incropera, D. P. Dewitt. Fundamentos de transferência de calor e de massa. 6. ed., Rio de Janeiro: LTC, (2008) p.643.

[12] W. D. Jr Callister, Materials Science and Engineering: an Introduction. 7th Edition. Jonh Wiley and Sons. NJ (2007).

[13] O. G. Silva Jr, P. S. O. Patricio, R.B.C. Sales, Thermal viability studies of polymeric composites with curaua fiber (ananas erectifolius) using infrared thermograph with focus on ambience confort. In: Diversity: design/humanities. v. 1. (2014) p. 772-780.

[14] C. B. C. S. Alvarenga, P. H. R. Borges, R.B.C. Sales, M. T. P. Aguilar. Uso da termografia infravermelha para estudo da temperatura Superficial de microconcreto geopolimérico e de cimento portland. In: XXXVI Jornadas Sudamericana de Ingenieria Estructural. Uruguai, v. 1. (2014) p. 139-147. 